\title{
Theory of systems with chaos of chemical composition in nature and technology
}

\author{
(C) Mikhail Yu. Dolomatov ${ }^{1,2}$ \\ ${ }^{1}$ Institute of Physics and Technology of Bashkir State University. Zaki Validi St., 32. Ufa, 450074. \\ Bashkortostan Republic. Russia. Phone: +7 (917) 453-85-16.E-mail: mdolomatov@bk.ru \\ ${ }^{2}$ Ufa State Petroleum Technological University. Kosmonavtov St., 1. Ufa, 450062. \\ Bashkortostan Republic. Russia.
}

Keywords: chaos of chemical composition, the law of constancy of composition, laws of distribution of composition, multicomponent systems, daltonide, chemical systems with significant and small chaos.

\begin{abstract}
According to the theory developed by the author, a substance is built from statistical ensembles more general than atoms, molecules, and supramolecular structures, namely, from multicomponent systems with chaos of chemical composition (MSCC). Any imperfect substance exists in the form of multicomponent systems with chaos of composition and consists of an infinite number of components. It is shown that all natural and man-made substances are MHS, with varying degrees of chemical chaos. According to the theory, MSCC with small composition chaos are distinguished, which are identified as individual substances and systems with significant chaos - multicomponent mixtures. Natural MSCC with significant Gaussian compositional chaos include hydrocarbon systems, for example, natural gases, fuel fractions, gas condensates, space systems, for example, interstellar dust and gas clouds, geochemical, and biogeochemical objects. Technogenic MSCC are obtained by processing natural systems, such as coal tar, and oil refining. Biogenic MSCC include humic acids, blood plasma, etc. Individual substances (colorblind) are Poisson systems with chaos of chemical composition, or systems with small chaos of composition. MSCC are objects that manifest themselves as a whole in physicochemical processes. These systems are qualitatively different from conventional mixtures by a certain statistical law of the distribution of the composition according to physicochemical properties and have thermodynamic and kinetic features. For example, the Ministry of Agriculture does not comply with the law of consistency. To characterize such systems, it is proposed to use the informational entropy of the composition and the entropy of the diversity of components. The point of view on matter as a system with chaos of composition is justified, one of the laws of evolution of which is the increase in the entropy of the diversity of states, which is the source of evolution of the MSCC.
\end{abstract}

\section{References}

[1] M.Yu. Dolomatov. Some physical and chemical aspects of predicting the properties of multicomponent systems under extreme conditions. GWHO them. D.I. Mendeleev. 1991. Vol.35. No.5. P.632-638. (russian)

[2] M.Yu. Dolomatov. Fragments of the theory of real matter. From hydrocarbon systems to galaxies. Moscow: Chemistry. 2005. 208p. (russian)

[3] M.Yu. Dolomatov. Chemical physics of multicomponent systems. Part 1. Physical and chemical theory of complex organic and petrochemical systems. Ufa: Institute of Problems of Oil Refining and Petrochemistry of the Academy of Sciences of the Republic of Belarus, Ufa. technol. in-t of the service. 2000. 124p. (russian)

[4] M.Yu. Dolomatov. Physico-chemical bases of new methods of research of complex multicomponent systems. Prospects for practical use. Moscow: Tsniiteneftekhim. 1991. 72p. (russian)

[5] M.Yu. Dolomatov. Application of electron spectroscopy in the physical chemistry of multicomponent stochastic and complex molecular systems. Ufa: TsNTI. 1989. 47p. (russian)

[6] Universal history of Chemistry. The formation of chemistry as a science. ed.Yu.I. Solov'eva. Moscow: Nauka. 1983. 463p. (russian)

[7] Preparation and analysis of pure substances: Interuniversity collection of scientific research of N.I. Lobachevsky University. Gorky. 1986. 123p. (russian) 
[8] Chemical reagents and especially pure substances of the Scientific Research Institute of Chemical Reagents and Especially Pure Chemical Substances. substances; Issue 53. Moscow: IREA. 1991. 131p. (russian)

[9] M.Yu. Dolomatov, M.Yu. Zhuravleva. Distribution of molecules in the interstellar medium and cosmogenesis of oil and biosystems. Ufa: Publishing house GUP INKHP. 2012. 167p. (russian)

[10] A.S. Eigenson, E.G. Ivchenko. Some regularities in the dependence between the characteristics of sulfur and high-sulfur oils and the content of non-carbon components in them. Collection of Organic sulfur compounds. Riga: Znanie. 1976. Vol.1. P.18-41.

[11] A.S. Eigenson. Regularities of the component-fractional composition of oils. Chemistry and technology of fuels and oils. 1973. No.1. P.1-5. (russian)

[12] F.G. Unger, L.I. Andreeva. Fundamental aspects of oil chemistry. Novosibirsk: Nauka, Siberian Publishing Company of the Russian Academy of Sciences. 1995. 192p. (russian)

[13] R.Z. Safieva. Physical chemistry of oil. Moscow: Khimiya. 1998. 258p. (russian)

[14] O.A. Beiko, A.K. Golovko, L.V. Gorbunova, V.F. Kamyanov, etc. Chemical composition of the oils of Western Siberia. Novosibirsk: Nauka, Siberian Branch. 1988. 288p. (russian)

[15] N.D. Ruslanova. Coal chemistry. Moscow: Nauka. 2003. 316p. (russian)

[16] A.P. Gavrilchik. Transformation of peat in mining and processing. Minsk: Navuka i tehnika. 1992. $196 \mathrm{p}$.

[17] G.F. Bolshakov. Physico-chemical bases of application of fuels and oils. Theoretical foundations of chemmotology. Novosibirsk: Nauka. 1987. 207p. (russian)

[18] V.A. Alekseenko. Ecological geochemistry: Textbook. Moscow: Logos. 2000. 627p. (russian)

[19] Statistical comparison of volcanoes based on petrochemical information (Pauzhetsky and Tolmachevsky volcanic centers, Kamchatka). USSR Academy of Sciences, Far East. otd-nie, Institute of Volcanology. Preprint of the Far Eastern Branch of the USSR Academy of Sciences. Vladivostok. 1987. 30p. (russian)

[20] D.S. Orlov. Humic substances in the biosphere. Moscow: Nauka. 1993. P.16-27. (russian)

[21] D.S. Orlov. Humus acids of soils and the general theory of humification. Moscow: MSU. 1990. 325p. (russian)

[22] I.V. Perminova. Analysis, classification and forecast of the properties of humic acids. Diss... $d-R A$ Khim. Sciences. Moscow: MSU. 2001. (russian)

[23] B.V. Voitsekhovsky, A. Korma. Catalytic cracking. Catalysts, chemistry, and kinetics. Moscow: Khimiya. 1990. 152p. (russian)

[24] V.D. Ryabov. Chemistry of oil and gas. Moscow: Oil and Gas. 1998. 373p. (russian)

[25] Yu.P. Yampolsky. Elementary reactions and the mechanism of pyrolysis of hydrocarbons. Moscow: Khimiya. 1990. 216p. (russian)

[26] G.G. Valyavin, M.Yu. Dolomatov, A.I. Ilyasov, N.F. Yurchenko. Physico-chemical properties of thermolysis of complex hydrocarbon systems. Experiment. Theory. Technology of St. Petersburg: Nedra. 2017. 352p. (russian)

[27] F.G. Unger. Fundamental and applied aspects of the results of the study of oil dispersed systems. Ufa, Iizdatelstvo GUP INKHP RB. 2012. 264p. (russian)

[28] Y.L. Dumsky. Petroleum resin. Moscow: Khimiya. 1988. 168p. (russian)

[29] V.V. Korshak, N.I. Kozyreva, Yu.V. Korshak. Chemical individuals and heterogeneity of polymers. High molecular Weight coed. 1986. Vol.28. No.6. P.1177-1186. (russian)

[30] N.V. Kalashnichenko, M.Yu. Dolomatov, S.V. Desortsev. Electronic phenomenological spectroscopy of human blood in normal and pathological conditions. Theoretical and practical aspects. Moscow: Inter. 2010. $256 \mathrm{p}$. (russian)

[31] Chemistry and physics of molecules and grains in space. Nottingham Chemistry and physics of molecules and grains in space: A gentral. discussion. London. 1998. 532p.

[32] F.J. Lovas. Recommended Rest Frequencies for Observed Interstellar Molecular Microwave Transitions. J. Phys. Chem. Ref. 1992. P.181-272. (russian)

[33] M.Yu. Dolomatov, N.A. Zhuravleva. Thermodynamic models of the distribution of life-related organic molecules in the interstellar medium. Astrophysics and Space Science, Springer Science+Business Media Dordrecht. May 2014. Vol.351. Iss.1. P.213-218. (russian)

[34] M.Yu. Dolomatov, N.A. Zhuravleva. Statistical models of the distribution of the composition of organic substances in giant molecular clouds. High-tech technologies. 2012. No.6. P.32-37. (russian)

[35] M.Yu. Dolomatov, N.A. Zhuravleva. The Thermodynamic models of Molecular chemical compound Distribution in the Giant Molecular Clouds Medium. Applied Physics research. 2012. Vol.4. P.149-154. (russian) 
THEORY OF SYSTEMS WITH CHAOS OF CHEMICAL COMPOSITION IN NATURE AND TECHNOLOGY

[36] M.Yu. Dolomatov, M.Yu. Zhuravleva. Distribution of molecules in the interstellar medium and cosmogenesis of oil and biosystems. Ufa: GUP INKHP Publishing house. 2012. 167p. (russian)

[37] V. Feller. Introduction to probability theory. Moscow Mir. 1984. P.165, 197. (russian)

[38] M.Yu. Dolomatov, M.A. Kazakov, N.A. Zhuravleva. Simulation modeling of multicomponent stochastic systems. Theoretical foundations of chemical technology. 2017. Vol.51. No.5. P.555-559. (russian)

[39] S.M. Korotaev. Entropy and information, universal natural science concepts.

http://www.chronos.msu.ru/RREPORTS/korotaev entropia/korotaev entropia.htm

[40] M.V. Volkenstein. Entropy and information. Moscow: Nauka. 1986. 192p. (russian)

[41] V.N. Yarygin, V.I. Vasilyeva, V.V. Sinelnikova. Biology. Textbook. Vol.1. Moscow: High school. 2000. 448p. (russian)

[42] W.R. Ashby. Introduction to Cybernetics. Moscow: Mir. 1959. P.178. (russian) 